\title{
Perspectives of Foster-Care Providers, Service Providers, and Judges Regarding Privatized Foster-Care Services
}

\author{
Kristen R. Humphrey, Ann P. Turnbull, and H. Rutherford Turnbull III, University of Kansas
}

\begin{abstract}
This qualitative study examined perceptions of foster-care providers, service providers, and juvenilecourt judges regarding privatized foster-care services in Kansas. Kansas was the first state to privatize all foster care, adoption, and family-preservation services. Most states report either beginning to implement managed-care principles in their child welfare services or exploring this option. Fifty-eight interviews with 33 participants (youth in out-of-home placements, their parents, foster-care providers, service providers, and judges) were conducted. The impact of privatization on access to services (i.e., mental health, appropriate out-of-home placement, aftercare, family support and family preservation, and reunification), communication, caseload levels, and spending is discussed. Recommendations regarding these issues are presented.
\end{abstract}

In 1997, the Kansas legislature and governor, acting together, privatized Kansas's foster-care, adoption, and family preservation services. The decision to transfer operational authority from a state agency and its local/regional units to contract providers in the private sector was controversial in several ways. First, the state made this change without input from many of the stakeholders (i.e., judges, child-welfare workers, and families; Kansas Action for Children, 1998; Shepherd, 1997). Second, at the time, the state-run child-welfare system was experiencing difficulty (Kansas Chapter National Association of Social Workers, 1997; Legislative Division of Post Audit, 1998a, 2001). Several years before, Kansas was the target of a lawsuit that the American Civil Liberties Union (ACLU) filed on behalf of Kansas children (Sheila A. v. Finney, 1987). The lawsuit's settlement required that improvements be made, but the improvements that the state-run system made were inadequate (Legislative Division of Post Audit, 1998a). In response, the legislature prompted the state's child-welfare agency (Kansas Department of Social and Rehabilitation Services [SRS]) to take more positive action for improvement (Kansas Action for Children, 1998). Third, the governor also simultaneously was encouraging all state agencies to consider privatizing services in an effort to reduce state spending (U.S. General Accounting Office, 1997). In response to these legal and fiscal challenges, the state agency decided to privatize all child-welfare services except for child protective services. The process started in 1996, and in 1997 the state finished transferring services to private contractors.

The privatization decision remains controversial. Some family and child advocates want the agency to return to the former, state-operated system. Others believe that the agency should adhere to privatization but make additional improvements (Kansas Chapter National Association of Social Workers, 1997; Legislative Division of Post Audit, 1998b).

Kansas does not have quantitative data that will allow for statistical comparisons of the system before and since privatization. In fact, one significant barrier to the successful implementation of privatization was a lack of reliable data on which to develop a baseline for contractor funding (Snell, 2000). There was no clear idea about the cost or quality of care the state agency provided before privatization (Blackstone, Buck, \& Hakim, 2004). Furthermore, nearly 3,500 children were transferred to the private contractors in the first 3 months of privatization without all of their records on transferable computer files (Snell, 2000). In August 1997, SRS shut down their former computer tracking system and began the process of implementing a new system (Legislative Division of Post Audit, 1998c). This left considerable gaps in information.

When privatization began, James Bell Associates (JBA) began evaluating identified performance standards using aggregate data from several sources (James Bell Associates, 2001). JBA used information primarily from a database supplied by the agency and from the contract agencies, and the company interviewed some child welfare workers from the state agency and from the private agencies.

Problems with the data used for analysis proved significant. First, when the state agency privatized, it changed its database, so comparing the preprivatization data with privatization data became impossible (U.S. Department of Health 
and Human Services, 1998). Because the outcomes, or standards, changed over time, it is difficult to judge performance on these standards since privatization occurred. Furthermore, when the new contracts began, the state discontinued collecting outcome data on children referred under prior contracts (James Bell Associates, 2001). Although this information is useful, an accurate, quantifiable picture of trends over time is still not possible.

Moreover, the data lacked information about disability. There was no way to explore issues regarding disability quantitatively. Accordingly, the present study focuses on circumstances for youth with emotional or behavioral disabilities in foster care. After consulting numerous stakeholders about the best way to obtain this information, the researchers decided to ask youth, families (families of origin and foster families), service providers working with families, and judges about their experience with foster care. The researchers sought to find out what worked well and what needed changing to (a) comply with relevant federal and state laws and (b) serve families and children appropriately.

The population this study considers is older youth with emotional or behavioral disabilities, a group whose extensive, expensive mental-health needs can be particularly challenging in the foster-care system (Blumberg, Landsverk, EllisMacLeod, Ganger, \& Culver, 1996; Brand \& Brinich, 1999; Clausen, Landsverk, Ganger, Chadwick, \& Litrownik, 1998; Schor, 1988; U.S. Department of Health and Human Services, 1997). This group also may present more of a challenge than do other youth in finding adoptive placements (McMurtry \& Gwat-Yong, 1992; Olsen, 1982; Schmidt-Tieszen \& McDonald, 1998; Seaberg \& Tolley, 1986). Finally, the foster-care system was not designed especially for these youth (Barbell, 1995; Goldhaber, 2000). Those youth, parents, foster-care providers, service providers, and judges who participated in interviews provided insight into what works for some families and what changes are warranted.

\section{The Push for Privatization}

Reviewing Kansas's experience with privatization is instructive. A Child Welfare League of America study found that 29 of the 49 states that responded were implementing managed care or privatization principles, and another 12 were planning to do so (McCullough \& Schmitt, 1999, 2000). Other states or counties that are considering privatization may benefit from learning about the Kansas experience as well as the experiences of other child-welfare agencies that have privatized some or all aspects of their child-welfare services.

Increasingly, human services, educational services, and child-welfare services are moving toward privatization. For the past several years, federal, state, and local governments have introduced more privatization of programs (Public Employees Federation, 2004). For example, the No Child Left Behind Act focuses on privatization of educational services (National Education Association, 2004a), and private contractors have provided various education support services for many years (National Education Association, 2004b). Many correctional facilities have also been privatized. In addition, private forprofit and not-for-profit agencies that contract with state and local governments and receive cash transfers through Home and Community Based Services (HCBS) waivers and Supplemental Security Income (SSI) funds from consumers often provide developmental disability and mental-health services. Proposals to reform SSI include plans to privatize the program. Many states are privatizing management of Medicaidfunded mental-health services (Oliver, 2002).

\section{Child-Welfare Privatization}

In the 1970s and 1980s, privatization of child-welfare services expanded nationally. This expansion was the result of rising caseloads, shrinking budgets, limitations in staffing flexibility in public agencies, and spending restrictions at state and local levels (Nightingale \& Pindus, 1998). Yet there was no clear evidence that privatization is either more or less effective than public service delivery (Nightingale \& Pindus, 1998).

The switch to managed care in child welfare occurred without significant empirical evidence that managed care improves outcomes for children and families, or that it lowers childwelfare services costs (Courtney, 2000). The term managed care refers to a variety of systems designed to control utilization or costs of services (Scallet, Brach, \& Steel, 1997). Generally, providers in a managed care contract accept a fixed compensation rate for a range of services for a particular group of clients (Wulczyn, 2000). Controlling access and utilization are two central components of managed care. Within health and mentalhealth systems, control is exerted using a single point of entry, usually through primary care physicians who approve or deny the service provision based on managed-care organization criteria. In the child-welfare system, however, the court supersedes the decision-making ability of the child-welfare staff or managed-care organization (Embry, Buddenhagen, \& Bolles, 2000).

\section{Kansas Privatization}

The Kansas State Department of Social Rehabilitation Services contracts with private agencies to provide foster care, family preservation, and adoption services. Kansas was the first state to privatize delivery of all these services (Kansas Action for Children, 1998). Contracts were open for competitive bidding for each of the state's five regions for family preservation and foster-care services and for a statewide contract for adoption services. Three private providers were contracted to serve foster care until July 2000 (James Bell Associates, 1999). The total 
contract for each agency was based on the population that each served in its region of exclusive operation. These three agencies covered the entire state.

Each agency was funded under a fully capitated approach. Contractors received a single, fixed rate, referred to as a "case rate," for each child in their care, which replaced the traditional fee-for-service payments (Social and Rehabilitation Services of Kansas, 1996). The case rate was meant to cover all services rendered to respond to each child's needs while the contract agency served him or her (Kansas Chapter, National Association of Social Workers, 1997). Services included those that addressed children's mental-health needs, such as treatment and hospitalization, which Medicaid had previously paid on a feefor-service basis.

The single, fixed-rate or case-rate funding paralleled some capitation models of managed health-care organizations (Kansas Action for Children, 1998). However, this model was different from managed health-care organizations in an important way: Contractors in the health-care system control those included in their system, but agencies that SRS contracts must accept all children SRS refers. Contractors did have the option of referring a relatively small number of children to SRS to pay actual costs on a fee-for-service basis. One hundred fifty fee-for-service slots were available for children with "catastrophic" needs (e.g., severe mental-health problems, histories of multiple hospitalizations) for Year 2 of foster-care privatization (Legislative Division of Post Audit, 1998a). Five agencies later received foster-care contracts lasting from July 2000 to June 2004. The new contracts discontinued the case rate and initiated a per-month, per-child payment system (James Bell Associates, 2001b).

This article describes a component of a larger research project (Humphrey, 2002) and focuses on perspectives of judges, service providers, and foster-care providers regarding these research questions: (a) In what way(s) do youth and their families, foster-care providers, service providers, and judges think that privatization of foster-care services has affected their child/their access to services? and (b) In what other ways do youth and their families, foster-care providers, service providers, and judges think privatization has affected children and families?

\section{Method}

The investigator(s) used a Participatory Action Research (PAR) Committee for advice on development of the research protocol, implementation of research, and dissemination of findings. The purpose of the PAR Committee was to increase the likelihood that the findings would help the research project's intended beneficiaries (Breda et al., 1997; Gatenby \& Humphries, 1996; Penuel \& Freeman, 1997; Turnbull, Friesen, \& Ramirez, 1998). PAR is a research method that brings together researchers and stakeholders as equal partners throughout the research process (Breda et al., 1997) to pursue change result- ing from the research (Gatenby \& Humphries, 1996). The experience and knowledge of people who often are part of oppressed groups are valued and honored in PAR (Reason, 1998).

Research stakeholders (young adults who had been in foster care, foster-care providers, adoptive parents, service providers, child-welfare workers, child-welfare researchers, and judges) served on the committee. Committee members communicated via a listserv, which accommodated one member who was deaf and preferred this communication method. Most PAR members were involved on a regular basis. The level of contact varied throughout the study, with PAR committee members being consulted several times weekly during some phases but only once every several weeks during other phases. A few members with limited availability were consulted only occasionally. The PAR Committee was most helpful during development of interview guides and shaping of some of the questions. For example, some committee members wanted to ensure that participants were not encouraged to attribute problems in the child welfare system to privatization. They recommended asking questions that asked participants to think about their experience "over time" rather than "before privatization" and "after privatization." (When this was unclear, the researcher asked, "What do you attribute the changes to?")

Individual interviews and court document reviews were data collection sources. Interviews were semistructured (Honey, 1987) and sought information about youth in fostercare placements who had emotional or behavioral disabilities. As previously explained, the state agency lacks quantitative data about this population. Its databases (past and present) do not indicate which children have disabilities. Therefore, there was no simple way to identify this population for quantitative investigation, and quantitative methods were insufficient for obtaining the desired depth of information.

Qualitative methods, such as in-depth interviews and case studies, help researchers obtain information that might be missed if participants were restricted to "forced-choice" answers (Banyard \& Miller, 1998). Such methods are also warranted when one explores "why" something happened, the unanticipated outcomes of a policy, and potential solutions to problems (Marshall \& Rossman, 1995). When evaluating programs that are developing or changing as participants and conditions change, qualitative methods are useful (Woodhouse \& Livingood, 1991).

In addition, qualitative methods help draw out participants' stories. Humans understand life through narrative accounts (Ball, 1998) that can explain how people experience situations in which they live (Abma, 1998). Stories also are artifacts that help others understand the narrator's actions, thoughts, and feelings (Said, as cited in Ball, 1998). The thick description that qualitative methods generate often captures details through multiple voices and perspectives (Banyard \& Miller, 1998). Finally, narratives frequently bring the voices of those who have been silenced, including children, to the attention of policymakers (Hones, 1998). 


\section{Participants}

The research involved inquiry into five cases, to constitute a collective case study (Stake, 1998). Investigators sought data from varied geographical regions and from families that would provide maximum variation of the sample within the regions (Patton, 1990). The 33 participants were selected using purposive sampling in two steps. Sites were selected first, then the participant groups within those sites were chosen. When the study began, three private contractors provided foster-care services for the state, and investigators selected two sites within each of the three contract areas. Across contract areas, half the sites were rural and half were urban.

Berg (1998) suggested that one way of gaining entry into, and establishing initial relationships in, qualitative investigations is to find a guide, that is, a person indigenous to the group under study. This guide can help the researcher connect with other potential participants and "vouch for" the researcher. This process, sometimes called snowballing, helps build up the sample (Berg, 1998).

Through the PAR Committee process, investigators identified a "guide," who was a respected district court judge and helped select sites by identifying other potential judges. The investigators then contacted SRS area chiefs in those areas. SRS and the judges were essentially gatekeepers of the data (Berg, 1998). The area chiefs chose a social worker or social work supervisor to identify families who fit study criteria and would provide maximum variation within the sample (Patton, 1990). Because the researcher knew some families would not participate, she asked SRS contacts to identify six families for each single family desired. To maintain confidentiality, SRS contacts identified potential participants without sharing identifying information with the researcher. The agency received packets of information explaining the study and asking for participation, and then the agency mailed the packets to the potential families. Families willing to participate filled out brief informational sheets and returned them to the researcher, who later contacted them to determine if they met study criteria. In sites where more than one family was willing to participate, researchers chose the family that best met the criteria.

Five families participated in the study. One sibling pair participated, so there were 6 youth participants. The youth and their families of origin were selected from five areas of the state. Three families were from counties with a population over 170,000 . Two of the families (three youth) were from counties with a population of less than 41,000 . Three families were European American, one was African American, and one was Hispanic and a native Spanish speaker. The lead researcher sought one or two primary caregivers from the family the youth had lived with before entering out-of-home placement. In two cases, this was a biological parent. In one case, two adoptive parents had reared the youth since infancy; in two cases, it was a biological parent and a stepparent. Table 1 highlights demographic characteristics of the youths. Two youths were female, and four were male; they ranged in age from 11 to 17 , and each youth had emotional or behavioral disabilities. Their diagnoses included depression, oppositional defiant disorder, attention-deficit disorder, adjustment disorder, and bipolar disorder. In addition, one youth had borderline intellectual functioning and another had mental retardation. Two of the parents had histories of depression, and five of the parents (of four of the youth) had histories of substance abuse. Domestic violence had been an issue in three of the families, and poverty affected three families.

The lead researcher sought a foster-care provider in each case. One youth had spent most of his time in out-of-home placement in a residential setting. In this case, the lead researcher asked his parents to identify someone in the residential setting who had the most experience with and had developed a relationship with the youth. Another youth had lived only in residential settings when the study began, so the lead researcher asked her parents to identify someone in the residential setting. Through the course of the study, the youth entered a foster-care placement, so the foster-care provider was also interviewed. Each foster-care provider was European American; one was male.

Service providers were identified by each youth, or by his or her family, as having been particularly helpful since the family became involved with the child-welfare system. Those service providers who had been particularly helpful were sought for their understanding of what was working and to focus on solutions. One service provider worked at one of the private foster-care agencies. During the course of the study, she switched to the new contractor in her area when the contracts changed. Two service providers were from a family-support agency. One service provider was from SRS, the state's child welfare agency, and two service providers were from area mental-health centers.

The judges presided over child-in-need-of-care cases. Five of the judges were involved in the youth participants' cases; two additional judges were also interviewed. These judges were from areas where study families had been sought but no families meeting the criteria were identified. All seven judges were European American; three were female and four were male.

\section{Data Collection}

Participant interviews were the primary data source for this study, and court case files were also examined. The senior author conducted 58 interviews with 33 participants over an 8month period. The interview process was similar but not identical among the various stakeholders represented. During the interviews, the senior author used an interview guide of open-ended descriptive questions that allowed participants to bring up issues important to them (Kadushin, 1990; Taylor \& Bogdon, 1998). A separate interview guide was used for each stakeholder group. Interview guides were three to five pages long, similar in structure and questions, and customized for each stakeholder group. Individual interviews with members 


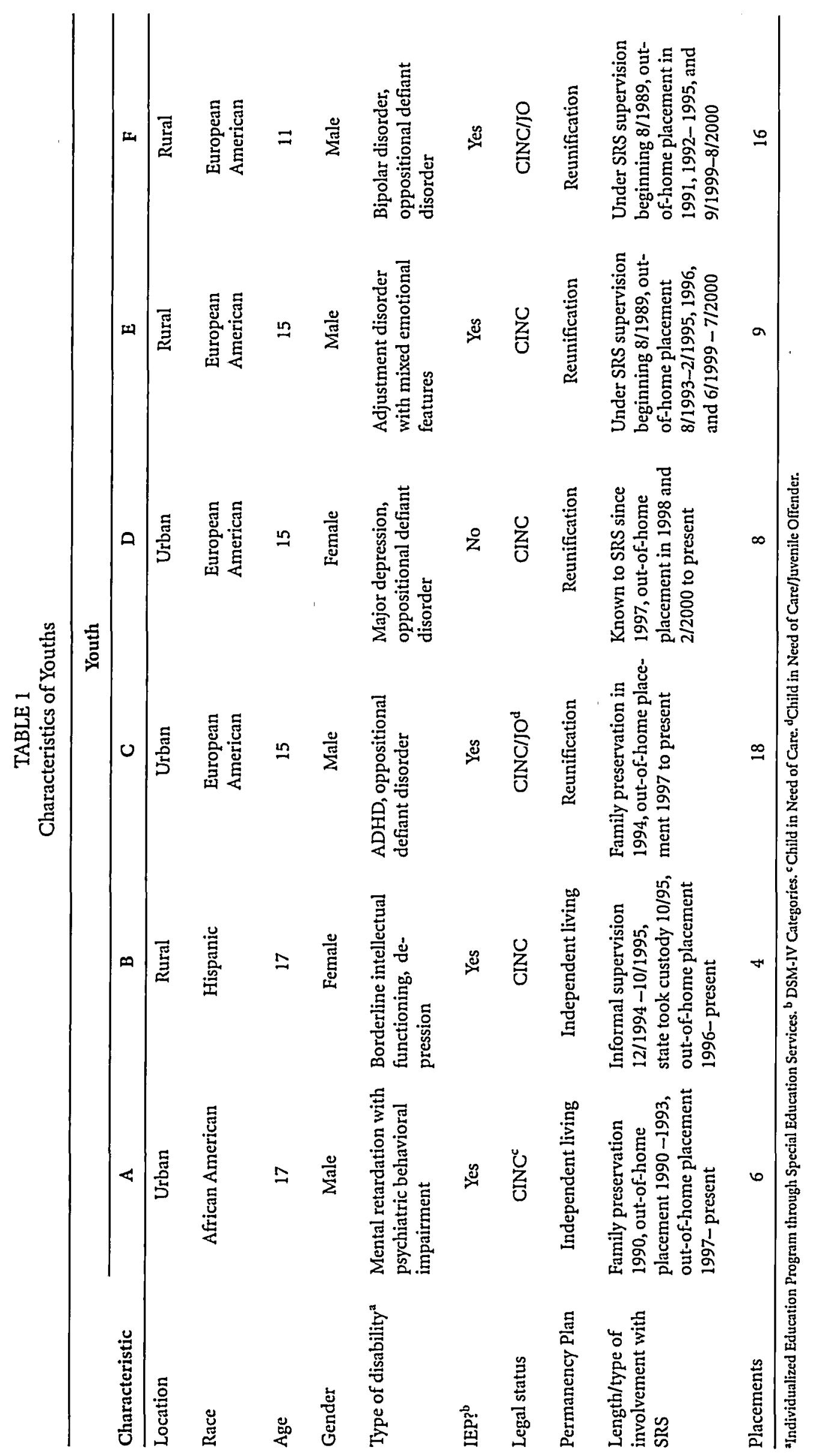


of the participant groups took place in locations of the participant's choice. Each youth interview generally took about $1 \mathrm{hr}$, parent and foster care provider interviews ranged from 1 to $3 \mathrm{hr}$ each, and service provider and judge interviews each lasted about $2 \mathrm{hr}$.

The youth in out-of-home placement, parents, and fostercare providers were interviewed on two or three occasions. In the first interview, participants answered questions that allowed them to "tell their story" of their experience with outof-home placement (Morse, 1994). Beginning an interview with "free recall" followed by more direct questions is a recommended technique for interviewing children (Docherty \& Sandelowski, 1999). Steward and Steward (as cited in Docherty \& Sandelowski, 1999), in a study that utilized both free recall and specific and direct questions, found that information from free recall was consistently more accurate than information gathered from specific or direct questions.

Once the participant told his or her story, the senior author moved into a semistructured interview (Honey, 1987). After the first interview, she reviewed what was discussed during that interview and read its transcript whenever possible. Reviewing the first interview helped develop a question guide for the second interview (Taylor \& Bogdon, 1998). After the second interview, the same process determined if a third interview was warranted. If it was, a third interview, involving one of the youth's parents and one of the youth's foster-care providers, took place.

Service providers and judges were interviewed on two or three occasions. The interviews were semistructured and took place in a location each of the participants chose. The subsequent interviews followed up on topics that were not fully covered in the first interviews. A third interview with two of the judges took place. The interviews focused on the specific families as well as the service providers' and judges' general experiences with foster care. Table 2 provides sample interview questions.

Information was culled from each youth's court case files and court social history files. The judge who was assigned to each youth's case provided these documents. The senior author made note of the youth's special education status, if applicable; the youth's psychiatric diagnosis, if applicable; the youth's age at the time of first out-of-home placement; his or her number of out-of-home placements by type; the youth's total amount of time in placement; cited reason for out-ofhome placement; court orders in place for the youth (e.g., visitation, therapy, psychological evaluation); court orders in place for the parents (e.g., visitation, therapy, drug/alcohol evaluation, parenting classes); whether siblings were also in out-of-home placement; the past and current permanency plans; and, the types of services the youth was receiving. The senior author used this information to obtain more information about each family's history with child-welfare services (including family services, family preservation, and foster care), to fill in gaps in information, and to cross-check information received from participants. Table 1 presents much of this information.

\section{Data Analysis}

This phase began with recording and transcribing interviews and entering court document review notes in a word processing file. Next, these materials were converted to Ethnograph files. The Ethnograph, a code-and-retrieve computer software program, was used for data analysis ("The Ethnograph," 1998).

TABLE 2

Sample Interview Questions

Participants were asked questions such as the following:

What has your experience with foster care been like, in general?

What, if any, changes have you seen over the years? What do you attribute these changes to?

Could you tell me about your experience with this child and his/her family?

What events/circumstances led to this child's placement outside of the home?

What do you think might have prevented this child's removal from the home?

What services are being provided to help with the child's return home or move to a permanent placement?

I'm going to ask you about several entities that provide services to children and families. I'm interested in what you think they do that is helpful and what you would like them to keep doing, as well as what you think is not helpful and what you would like them to do differently. First, let's talk about child-welfare agencies:

What do you think they do that is helpful and that you'd like them to continue doing?

What do you think they do that is not helpful?

What would you like them to do differently?

(Same question then repeated for other agencies such as mental-health agencies, schools, courts)

Note. These questions are provided as samples. They are not all-inclusive, probes were deleted for the sake of brevity, and the question guides were structured differently 
Fifty-eight transcripts from interviews and 5 files from reviews of court documents were analyzed. Analysis involved putting information in chronological order, making matrices of categories and placing evidence in them, and creating displays for examining data (Miles \& Huberman, 1994; Taylor \& Bogdon, 1998; Yin, 1994). Analysis began with inductive theory construction (Miles \& Huberman, 1994; Taylor \& Bogdon, 1998). The senior author and an assistant read the first 12 transcripts and independently assigned code words describing sections of the text. Next, the researchers assigned codes to transcripts without a predetermined list of code words. Some sections of text had only one code word, whereas others received more than one code word. The researchers met and discussed each coded block of text. When these blocks of text were coded differently, the researchers discussed them until reaching consensus. The senior author made final decisions about coding.

Initial readings and discussions generated a provisional code list. The senior author reviewed the research questions to ensure that there was a code that represented each research question. A third researcher read each transcript and filled in a grid that included each research question (Miles \& Huberman, 1994). There was a separate grid for each stakeholder group (i.e., one grid represented judges, one represented service providers, one represented foster-care providers, one represented parents, and one represented youths). This provided a snapshot of what each stakeholder group reported (Miles \& Huberman, 1994). The senior author also recorded a chronology for each family, with information such as the timeframe and circumstances surrounding the family's initial involvement with SRS; when the child(ren) entered state custody and out-of-home placement; what placement moves occurred; and what services youth and their families received before placement, during placement, and after reunification, when applicable.

After filling in the grids, the third researcher also coded each transcript. The senior author then compared the two sets of coded transcripts. If there was disagreement, the researchers discussed it until reaching consensus. Again, the senior author made final coding decisions. As coding continued, codes were added and refined until a final coding guide was developed. This process resulted in eight versions of the coding guide. When the final coding guide was complete, the senior author returned to transcripts coded with earlier guides and recoded them with the final coding guide. When final coding was complete, there were 24 code categories and 103 subcode categories. The Ethnograph facilitated the data-organization process ("The Ethnograph," 1998). Transcript excerpts from each code category were then reviewed and analyzed (Miles \& Huberman, 1994; Taylor \& Bogdan, 1998).

After all transcripts were coded, the senior author considered the volume of available information and determined that the inductive approach yielded many more code categories than were necessary to answer the research questions. Next, the senior author reviewed the code categories and determined which codes answered the research questions. This approach was consistent with using the theoretical orientation to guide analysis and to focus attention on certain data and filter out other data (Yin, 1994). The Ethnograph was then used to sort information relevant to each research question. Next came analysis of sorted transcript sections. The senior author examined the information in two ways: (a) by family group (i.e., a youth, his/her parent(s), foster-care provider, service provider, and judge) and (b) by stakeholder group (i.e., the youths, the parents, the foster-care providers, the service providers, and the judges). Summaries were drafted for the topic, or code chunks, under analysis. In some cases, categories had to be broken down into smaller categories for comprehension.

Credibility (the extent to which others are confident that the participants and area under study are being presented accurately) was enhanced by data triangulation (Denzin, 1994; Erlandson, Harris, Skipper, \& Allen, 1993; Lincoln \& Guba, 1985). Triangulation occurred in three ways: (a)collecting information from multiple sources (youths, foster-care providers, families of origin, judges, and service providers), (b) obtaining information through more than one method (document analysis and in-depth interviews), and (c) involving at least two researchers in the analysis (Erlandson et al., 1993). In addition, member checking was conducted with participants throughout the interview process by confirming impressions and clarifying information gathered in previous interviews (Erlandson et al., 1993). All participants who could be located (70\%) received summaries of findings via the U.S. mail, which provided opportunities for them to respond. The senior author included paper, a self-addressed stamped envelope, and a toll-free telephone number so participants could respond easily and without personal expense. Throughout the analysis, the senior author occasionally presented tentative findings to the PAR Committee for comments. After the final analysis, a summary of findings was presented to the PAR Committee, and members were asked to comment on the findings. No responses from participants or from PAR Committee members contradicted the findings.

An audit trail and peer review supported credibility and dependability (the concept parallel to reliability in quantitative research; Erlandson et al., 1993; Schwandt \& Halpern, as cited in Huberman \& Miles, 1994). Confirmability (which addresses the issue of whether someone else could look at the puzzle pieces and see how the researcher could have reasonably put the puzzle together) was enhanced through use of a reflexive file, maintenance of an audit trail, and completion of a confirmability audit (Erlandson et al., 1993; Marshall \& Rossman, 1995). An outside expert researcher conducted this audit during the latter part of data analysis.

\section{Results}

A lack of consensus existed regarding the merits or flaws of privatization of foster-care services. Participant views on privatization ranged from the sentiment that privatization will 
continue to improve, to the view that foster care should no longer be privatized. No participants spoke strongly in favor of privatization. On the other hand, only one participant asserted strongly that foster-care services should not be privatized and that Kansas should end privatization.

All participants were affected by privatization in some way, but not everyone was aware of the ways in which privatization influenced them. Each of the judges, many of the service providers, and many of the foster parents spoke about privatization directly and how it affected them. Neither the biological parents nor the youth talked about privatization directly.

Participants identified (a) ways that privatization of fostercare services affected access to services and (b) the impact of privatization on communication, caseload levels, and economic issues. The following is a discussion of study findings according to these two themes.

\section{Impact of Privatization on Access to Services}

Participants described ways that privatization influenced access to various types of services. They addressed (a) mental-health services, which cut across all the other services; (b) services resulting from investigations of child abuse and neglect (family services, family preservation, and out-of-home placement); (c) services provided during out-of-home placements (reunification and appropriate placements); and (d) services after reunification (aftercare; see Figure 1).Participants reported both positive and negative impacts for some types of services, and only negative impacts for other types. The following sections indicate whether participants reported the overall impact as only negative (with no positive impacts noted) or mixed (both positive and negative impacts noted or conflicting viewpoints noted).

Mental Health Services: Negative Impact. Participants were concerned about how access to mental-health services diminished after privatization, because (a) the contractor did not provide mental-health services, (b) the contractor provided mental-health services but only "in house" instead of contracting out for services, (c) the contractor worked only with certain providers and approved only certain therapies, or (d) the contractor relied on the mental-health consortium that was slow to assess children.

One foster-care provider cited problems with ensuring that the contractor followed through on mental-health recommendations for youth in his care. For example, the mentalhealth center from which the youth had been receiving services recommended group therapy:

They just never set it up. They never took any action on it, and we would suggest it and suggest it at case plans.... See, I can't do it .... Before, it was kind of left up to the foster parents, like with [mental-health center], it was left up to us to contact the people. We could call them, we could set it up, and we could go ahead and take them, and that's how we did it. But now, going through the system like we have to now, we have to go through [contractor], and we have to count on them. Well, if you're not doing it yourself, you can't count on them getting it done, and then it just kind of comes to a dead end.

Two service providers expressed doubts about the introduction of privatization in regard to mental-health services. One explained that privatization has affected access because foster-care contractors work with mental-health providers who may not provide adequate services for trauma issues. She said, "We seem pretty tied to the ones [the contractor] has contracted with, and those aren't always the best-in-the-field trauma counselors." The other service provider stated that services to children have been "cut back" due to privatization. Specifically, she worried that the contractor for her area did not believe that young children should receive therapeutic services for sexual abuse. One service provider was concerned about the mentalhealth consortium that reviewed requests for services. According to her, the consortium was slow to assess children.

Appropriate Placements: Negative Impact. Some participants believed that privatization had resulted in a lack of appropriate placements for children and youth. Their perception was that under privatization, contractors place youth in settings that do not address the youths' needs adequately (e.g., a family foster home instead of a residential facility). A fostercare/service provider said that privatization looks good on paper and works well for young children but called it a "nightmare for teenagers." She believed that family foster homes that are readily available are adequate for young children, but many youth in the system have needs that require a setting that is more specialized. She stated that by the time privatization took effect, Kansas faced a shortage of resources for youth that privatization made worse. Moreover, she said that youth with severe problems had few placement options. Kansas has a focus, she said, on moving youth from residential centers or group homes into foster homes, but some youth do better in a group home and cannot succeed in a foster home. Furthermore, when contractors placed youth in appropriate treatment settings, they expected the youths' problems to be treated in 3 to 4 months' time.

Another foster-care/service provider also believed that there are insufficient placement options but sees the problem differently. She said that the courts are sending children and youth into residential placements more quickly than before privatization. Sometimes, she said, these youth must stay in residential facilities past the necessary length of time because less restrictive placements, such as foster homes, are unavailable.

Aftercare Services: Negative Impact. There was agreement among the few participants who noted lack of access to aftercare services. They stated that after the court terminated 


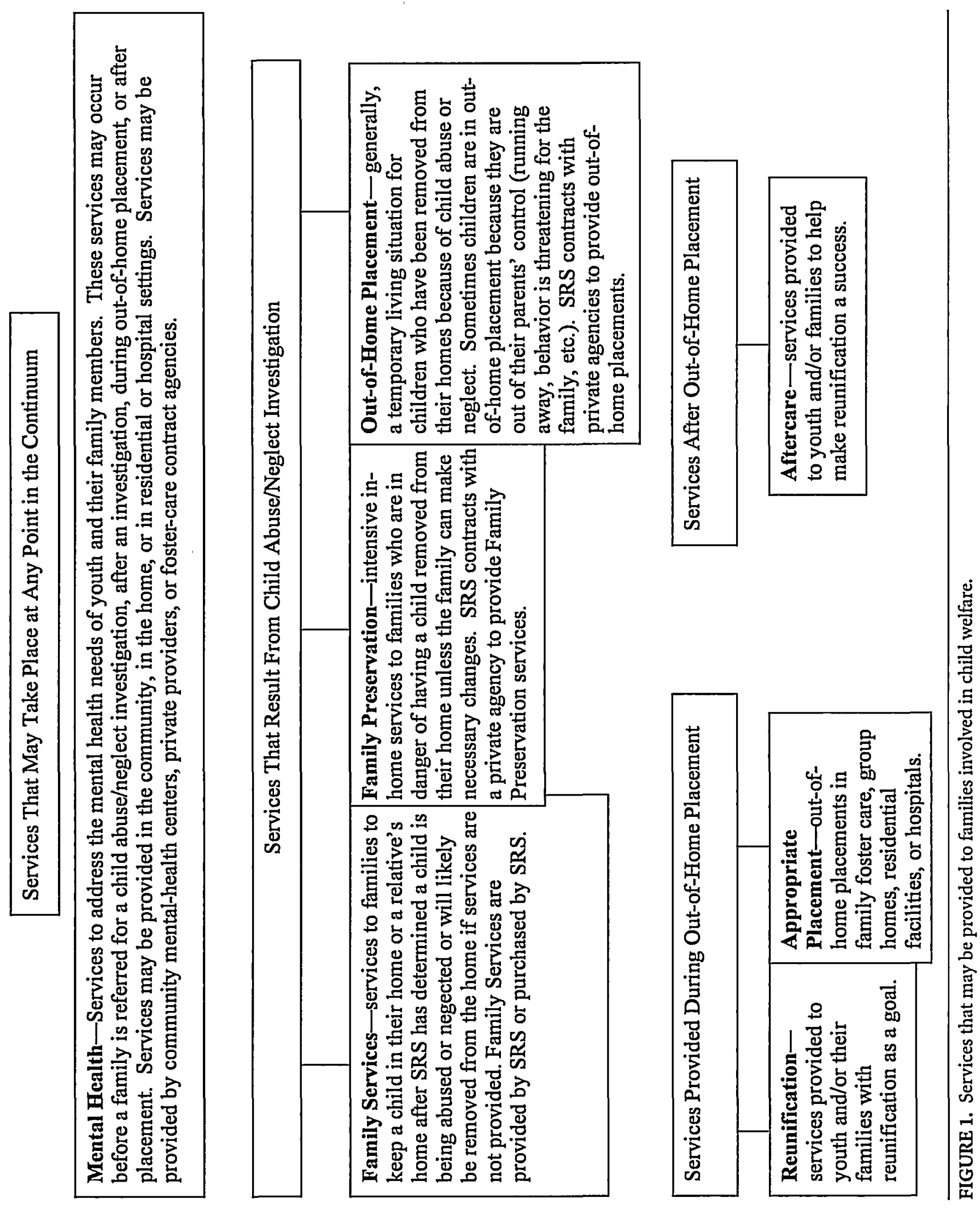


a youth's parents' rights, services to the youth stopped while the youth waited in "limbo" for permanent placement. Fostercare contractors do not receive additional funding for aftercare services; this was cited as the reason for contractors' neglecting aftercare services. A foster-care provider explained:

They're supposed to be getting [aftercare] services. But I would say out of the 39 kids I've kept contact with, I only know of two or three where there's been services afterward. They might show up that first month, or they might not show up at all and they just never do. It's not being done. And why would it? They're not getting extra money for it to be done.

Family Services, Family Preservation, and Out-of-Home Placement: Mixed Impact. Some participants believed privatization made SRS more likely to recommend family preservation services or out-of-home placement. According to some, this was because SRS had more resources to investigate families after privatization. Others believed that SRS was more likely to recommend these services because it was not responsible for providing them .

Some participants believed that privatization facilitates access to services that prevent out-of-home placement. They found in privatization an increased emphasis on using family preservation to avoid out-of-home placement. This emphasis seemingly was driven by SRS, which some said recommends family preservation to reduce the number of children in foster care.

Other participants believed that preventive services are more difficult to access because of privatization, and that SRS provided more basic family services before privatization. A judge offered an example:

When I order a parent to take parenting classes, and they try to get them through SRS, they're given a video to take home and do on their own. That's not very satisfying, and I'm not sure it's very helpful. I can remember when workers would go into the home and help them do their laundry or walk them through it. Talk to them about organizational tips, structure ideas for children. You know, meeting their needs for structure. On the scene. That wasn't Family Preservation. That was just Family Services. That's not happening now. That's a concern that we're just not ... we don't have the services for the families that we had in the past.

Some participants asserted that SRS recommends more services for families than in the past, but they also indicated that these services are more likely to be out-of-home placement than preventive services.

Reunification Services: Mixed Impact. One participant said that, before privatization, families had to "straighten up" on their own but that, now, privatization gives biological fami. lies access to services geared toward reunification. More participants believed that children and families are less likely to receive services during out-of-home placement. Before privatization, some participants explained, families were more likely to receive services that would help with reunification while their children were in care. Those services either are not offered now or, if they are offered, are less appropriate services or of lower quality. This was especially noted with mental health services and appropriate placements. For example, a judge explained that it has been difficult to obtain parenting evaluations under the new private contracts:

The parenting evaluation makes recommendations as to what the parents need to do to become better parents. If I don't have that, I don't know what services they really need. So, as a result of privatization, I feel like they're not getting all the evaluations that lead to the services they need.

A foster-care/service provider explained that there is a lack of appropriate settings for some youth, saying, "The acute cares have just disappeared. The other end of that spectrum is to secure the state hospitals, the acute cares, the ones that they need to be there don't exist any more."

\section{Impact of Privatization on Communication, Caseload Levels, and Economic Issues}

In addition to service access, participants talked about the effect of privatization in general. Participants spoke of communication problems, caseload levels at contract agencies and at SRS, and economic issues.

Communication: Negative Impact. Some participants discussed communication problems that occurred because of privatization. Judges described problems with SRS and the contract agencies' efforts to shield the court from disagreements among SRS and the contract agency workers. In some cases, SRS would not allow contract agency workers to be present at court or to disagree with the position the SRS case manager presented. SRS and contract agency workers were expected to present a "united front" in court. In other cases, SRS and contract agency workers simply did not communicate with one another. A judge reported having to intervene between SRS and a contract agency, saying:

SRS didn't know what [contractor] was doing.[Contractor] didn't know what SRS was doing. SRS even requested that $I$ order that [contractor] cooperate with SRS and give SRS the documentation that they would need on a given case because there wasn't any communication between the two agencies. I don't know why; they're on the same side. So I had to do that a time or two. 
A few service providers also expressed concerns about communication because of privatization. An SRS worker explained that it was difficult when a family on her caseload had a contract agency service provider who would not communicate with SRS. She explained, "You don't have control over it. I mean you can try to have control over it, but it all depends on the worker that you get. And you can't ask to have workers switched. So if you get a worker who doesn't communicate, you're in a mess." Another service provider attributed a feeling of "not working together" to privatization. She explained that it feels as if the agencies are doing their jobs independently of one another, and that the agencies and families are "not connected."

Caseload Levels and Staffing: Mixed Impact. Many participants explained that caseloads were too high for case managers at the private foster care agencies. When privatization occurred, participants explained, the contractors were not adequately prepared for the numbers of families and the intensity of needs they were charged with when they received the initial contracts.

The contractors soon realized they needed to increase their staff. The agencies had a difficult time finding staff with experience in child welfare and who were qualified for the positions. Many employees who had initially been hired by contract agencies soon left for other employment opportunities, forcing the agencies to search once again for qualified staff. A judge explained,

As soon as [ the contractor] started, they had to double their staff. To get qualified committed social workers with any experience was almost impossible. So we had a bunch of new people, or people that were not able to maintain employment somewhere else in the social service arena, to be perfectly candid. They did not maintain for any continuing period of time, because even with doubling the size of their staff, the caseload work was so intensive that there was a great deal of burnout. And a great deal of them, of the social workers, simply said, "I can't deal with this pressure. This is not what I want to do. I don't feel like I'm being of benefit. I'm not going to do this."

This turnover in staff caused problems for families. From start to finish, a family might have had five or six case managers. Families were confused and had trouble reaching their case managers. Consequently, continuity of care was compromised.

In contrast, some believed that caseload levels for SRS workers have improved because of privatization. Although most of the focus on caseload levels was on contract agencies, two participants mentioned a positive benefit to child-welfare workers at SRS.

Economics of Privatization: Mixed Impact. Many participants spoke about economic issues related to privatization, and some believed that funds are better managed under privatization. Others maintained that agencies are making decisions on the basis of financial concerns instead of what is best for children and families.

Some who thought that spending issues had improved with privatization explained that contract agencies have negotiation power with other area agencies that provide services to families. One participant said that prior to privatization, SRS was motivated by money to keep children in their homes. With private contractors providing foster-care services, SRS no longer is motivated to avoid out-of-home placement.

Some participants shared concerns that the agency suffers because it provides a level of service that does not fit within its budget. Other participants worried that contractors reunify families because of financial pressure to get families out of placement. One participant explained,

It's like you want all this cohesiveness, but the bottom line is if you're the contractor you're kind of in managed care. You have to watch the dollars... well, I shouldn't say they're only watching the dollars, because their other job is to get these kids back home. Bottom line is, if you don't get them back home, you're spending this money, and you only have so much to spend. So there's an incentive to do that, too. All of a sudden, people that you've always worked well with, all of a sudden, you're not working with them. You're saying, "What happened? Did you sell out to managed care?" And this person that worked with you five months ago [and] was saying, "Don't people get it that these kids need to be here longer?" [is] suddenly arguing the other side, and you're sitting there going, "Wait a minute. What happened?"

\section{Discussion}

Perspectives of stakeholders may provide information on which to base recommendations and further research. This discussion includes a brief summary of the research findings, recommendations, and limitations.

\section{Summary}

Participants in this study shared their perceptions of privatization's impact on foster care services in Kansas. Participants' responses are briefly summarized below. Participants perceived that

- Mental-health services were more difficult to access after privatization.

- Privatization has led to lack of appropriate placements for youth 
- Aftercare services have been inadequate since privatization.

- SRS is more likely to recommend either family preservation or out-of-home placement since privatization.

- Privatization led to communication problems among professionals.

- Caseload levels at private agencies are too high.

- Turnover in staff was high in private agencies.

- Caseload levels at SRS have improved.

- Furthermore, most believed that families receive fewer services while their children are in care than in the past.

- Some believed that funds are better managed under privatization; others believed that agencies make decisions on the basis of financial concerns rather than the children's best interests.

- There was disagreement regarding whether preventative services are easier or harder to access now than in the past.

\section{Recommendations}

In the following section, recommendations are discussed according to the two main themes: (a) impact of privatization on access to services and (b) impact of privatization on communication, caseload levels, and economic issues.

Impact of Privatization on Access to Services. Participants addressed perceptions of the impact of privatization on access to services. They addressed (a) mental-health services, which cut across all the other services; (b) services that result from investigations into child abuse and neglect (family services, family preservation, and out-of-home placement); (c) services provided during out-of-home placements (reunification and appropriate placements); and (d) services after reunification (aftercare).

Mental-health services. Many participants shared concerns about access to mental-health services. This was a concern from prevention of out-of-home placements to services during placement. Making mental-health services available and accessible to youths and their families before crises occur should be a priority. Inaccessibility of mental-health services can contribute to family crises. For example, Petr and Barney (1993) interviewed 26 families whose children had developmental disabilities, emotional disorders, or technology-support needs. One half of the 26 families reported experiencing a crisis that threatened the child's placement during the 6 months before the interview. Crises most frequently reported involved the child's behavior and needs, that is, running away, not sleeping, depression, or medical problems. The crises mentioned with the second highest frequency were system-related, in that a professional outside of the family decided that the child would be better off outside the home. These parents perceived that professionals were oriented toward substitute care as a preferred solution to problems, as contrasted with providing mental health and other services to enable children to stay with their families (Petr \& Barney, 1993).

Indeed, the General Accounting Office (GAO) recently reported that 12,700 children were placed in child welfare or juvenile justice settings in just 28 states in fiscal year 2001 to access mental-health services (U.S. General Accounting Office, 2003a). Although this practice is against agency policy in Kansas, two of the youths in this study went into care to obtain mental-health services.

Although children in the study had access to mental health services while in out-of-home placement, the services were often viewed as inappropriate or inferior. This is consistent with reports in the literature that far more youth need mental-health services than actually receive these services, and that youth who do receive services often receive inappropriate or ineffective services (Julian, Julian, Mastrine, Wessa, \& Atkinson, 1992; Rosenfeld et al., 1997; Saxe, Cross, \& Silverman, 1988). Sometimes children and youth are unable to receive mental-health services until they have serious emotional disorders (U.S. Public Health Service, 2000). There is a shortage of evidence-based treatment for youth with mental-health needs, and much of the evidence that is available is not put into practice (U.S. Public Health Service, 2000). Youth who receive mental-health services often experience fragmented services, outmoded service models (U.S. Public Health Service, 2000), discontinuities in care, obstacles to family involvement, and transfers from one provider to another (Julian et al., 1992; McKelvey, 1988).

Knitzer (2001) outlined several qualities of effective mental-health services for young children. These qualities are appropriate for older youth as well. To be effective, mentalhealth services should be (a) appropriate to each child's developmental level, (b) relationshipbased, (c) supportive of the family as a whole, (d) infused into existing childhood networks and services, (e) responsive to the community and cultural context, and ( $f$ ) attentive to outcomes.

Appropriate placements. Participants reported that appropriate placements for youth were often hard to obtain. This was especially true for youth who had severe problems or were in need of long-term treatment for issues such as sexual offending. However, participants also reported that some youth stayed in residential facilities longer than necessary because family foster homes were unavailable.

Youth should be in placements appropriate to their needs. Placing a child who needs specialized services in a regular foster home does a disservice to all involved. Children with unmet behavioral needs are more likely to experience changes in placement (Hartnett, Falconnier, Leathers, \& Testa, 1999). Conversely, children are more likely to be "stabilized," especially those identified as delinquent or oppositional, if they are in specialized foster care settings rather than in regular foster homes (Hartnett et al., 1999). Furthermore, "stepping down" from specialized placement to a regular foster home can be problematic when it involves physical movement from one set- 
ting to another. Researchers found that children who were physically moved from specialized placement to a regular foster home subsequently experienced 3 times more moves than did children who remained in the same home (Hartnett et al., 1999).

Aftercare. A few participants expressed concerns about aftercare services, saying that youth who are reunified do not receive aftercare services that the foster-care provider is supposed to provide. Three of the families experienced unsuccessful reunification, at least partly because of inadequate preparation for the return and inadequate support after the return.

Poverty, housing troubles, and children's medical or behavioral needs are related to reentry into out-of-home placement (Jones, 1998). Families in this study could have benefited from, or could benefit from when reunification occurs, aftercare services that address those issues. Services that might have been especially helpful to the study families include (a) a period of transition that includes part-time out-of-home placement, (b) in-home services to assist with the youths' problem behavior, (c) respite care, (d) attendant care, and (e) mentalhealth services for the youths and their families.

An external evaluation of the Kansas Child Welfare system identified aftercare services as an "underdeveloped area" (James Bell Associates, 2001). This is disconcerting because, since privatization took effect, approximately $25 \%$ of youth who reintegrated with their biological families reentered outof-home placement within a year (James Bell Associates, 2001).

Family services, family preservation, and out-of-home placement. Each participant family received some type of services before out-of-home placement, but in each case, the family was already in crisis. For each family, it seemed to be a case of "too little, too late." Each of the families could have benefited from intensive mental-health services for youth and, in many cases, for parents as well. Services related to low-income benefits and assistance in dealing with a child's problem behavior would also have been important. Families needed services before being pulled into the child-welfare system. Perhaps if effective, appropriate services had been available, out-ofhome placement would not have been necessary.

Whenever possible, the state should provide services that carry the potential to prevent out-of-home placement. Ideally, prevention efforts should be primary prevention, which in child welfare involves early assessment and intervention when children are placed at high risk of maltreatment and negative developmental consequences (Dore, 1999). Family support services are one means of primary prevention. The intent of family support services is prevention of child abuse and neglect in families that are not yet in crisis. These services are usually based in the community. The goal of these services is to promote the well-being of children and families, increase families' strength and stability (including foster, adoptive, and extended families), increase parental competence, provide a stable family environment for children, and enhance child de- velopment (Ways and Means Committee, 1998). In addition to keeping families together, preventive services can save the state money. For example, using family preservation services may reduce the demand for foster-care services and thereby reduce the cost of child-welfare services. The director of Kansas's family preservation program explained, "A year in foster care at $\$ 2,000$ a month is $\$ 24,000$... Compare that with the $\$ 3,400$ we get for as long as the family needs services" (Rothschild, 2001 , p. a1). (The family preservation contractor receives $\$ 3,400$ for the entire length of service for a family. Most contractors report 3 to 6 months as common service duration (Pheatt, Douglas, Wilson, Brook, \& Berry, 2000).) However, using family-preservation services to prevent family crises earlier in the process could also result in more families' receiving this prevention service. Thus, rather than cost reduction, the result might be cost shifting.

Reunification services. Some participants reported that children and families are less likely to receive services during out-of-home placement, and one participant stated that biological families have greater access to services geared toward reunification because of privatization. Participants reported that under the new foster-care contracts, foster-care providers have refused to pay for some mental-health services that they provided in the past. One example is services for parents. Fostercare providers contend that their contracts do not require them to pay for services to parents and that their only responsibility is ensuring service availability (James Bell Associates, 2001). A typical service parents are expected to pay for under these contracts is a court-ordered mental-health evaluation. A participant reported paying $\$ 900$ for such an evaluation at the community mental-health center. This sort of practice puts families who are already struggling financially at further risk. If families are indeed less likely to receive services during outof-home placement, this could have a profound impact on children and families. Because of the Adoption and Safe Families Act's time limits, more than ever before, families need services that are timely, appropriate, effective, and accessible.

Impact of Privatization on Communication, Caseload Levels, and Economic Issues. Participants spoke about effects of privatization other than service access. Participants spoke of (a) communication problems, (b) caseload levels at contract agencies and SRS, and (c) economic issues.

Communication. Participants reported that communication problems between the private contractor staff and SRS staff exist. In addition, two judges reported that SRS should monitor private contractors more closely. SRS staff and private contractor staff have interdependent roles. SRS staff members are identified as case managers, but the private contractor staff members are responsible for case planning, service provision, and decision making on a day-to-day basis.

Training that provides workers with a common body of knowledge regarding roles of social workers and case managers from the state agency and the private agencies, relevant policies, services available to children and families, and court 
processes should be provided to workers across the state. In addition, providers would benefit from training that addresses interagency collaboration. To work collaboratively, professionals must be able to trust each other's opinions and feel that they can rely on one another (Roberts-DeGennaro, 1996). It is not enough to mandate new laws or policies to make professionals effective collaborators. Professionals must be socialized to communicate and collaborate with each other (Waugaman, 1994).

Caseload levels and staffing. Participants reported that caseload levels have been reduced at SRS but that the private contractors had caseload levels that were too high. A survey of 43 state child-welfare agencies and 48 county child-welfare agencies indicated that workloads that are too high or demanding, and caseloads that are too high, are the two reasons most often given for staff-turnover problems in child-welfare agencies (Tucci, 2001). (Workload is the amount of work expected of an employee; caseload is the number of individuals or families an employee is expected to serve.)

The National Association of Social Workers recommends a caseload of 20 to 25 families per social worker in child protective settings, and the Child Welfare League of America recommends a caseload of 12 to 15 per worker (NASW Task Force on Social Work Practice in Child Protection, 1997; U.S. General Accounting Office, 2003b). Keeping caseloads lower is one way to enhance staff retention. High caseloads and staff turnover disrupt continuity of services, delay timeliness of investigations, and limit frequency of worker visits (U.S. General Accounting Office, 2003b). Furthermore, burdensome caseloads are probable contributors to problematic relationships between service providers and families. Keeping caseloads lower will enhance the continuity of care for youth and families and make it easier for service providers to carry out their tasks.

Economics of privatization. Some participants believed that funds are better managed under the privatized system than before. However, others believed that agencies are making decisions on the basis of financial concerns instead of what is best for children and families. When child-welfare officials seek to privatize services, they may hope to coordinate services, control costs, ensure quality care, and develop innovative measurement and service delivery systems (Drissel, 1997). In Kansas, it is difficult to compare privatized child-welfare services to services before privatization. When Kansas privatized child-welfare services, SRS discontinued their previous database, started a new data-collection means, and created a new database that was incompatible with the previous one (U.S. Department of Health and Human Services, 1998). This made it impossible to accurately compare pre- and postprivatization outcomes. Nationally, there have been few evaluations of privatized child-welfare services (Embry et al., 2000), and there is no significant empirical evidence that managed care will improve outcomes for children and families or lower costs for child-welfare services (Courtney, 2000). This should be, and undoubtedly will be, a subject for future research.

\section{Limitations}

This research focused on youths with emotional or behavioral disabilities in out-of-home placements. One of the study's strengths was inclusion of in-depth information from a range of stakeholders. However, within subsections there were two few respondents from each group of stakeholders to sort out differences by location of the state or by stakeholder type. In addition, neither the youths nor the biological parents reported directly about privatization. Therefore, although they participated in the study and provided information relevant to other topics in the larger study, their perspectives are not included here.

Families were asked to nominate service providers who had helped the youths and/or their families. Therefore, service providers included in the sample were not representative of all service providers serving the youth but rather were selected on the basis of helpfulness. While this is a potential limitation, the research is not intended to generalize beyond the study sample. Rather, readers may determine the relevance to their situation and use the information to identify questions for future research.

A potential limitation of the study was its retrospective nature. It is likely that participants' immediate foster care experiences overshadow their experiences from the past. In addition, over the course of the study, the privatized system was continually changing. During the course of the interviews, the first round of contracts ended and new contracts began.

Two other limitations of this study were its small scale and grounding in the local context of the Kansas privatized child-welfare system. Likewise, conclusions could be different if the sample were drawn from a different subset of the fostercare population (e.g., cases for which abuse or neglect was the main issue leading to out-of-home placement). However, the reader may find relevance to other contexts.

Finally, the reader may seek simple answers to questions such as, "Is privatization of foster care services good or bad?" or "Are specific successes or challenges due to privatization?" There are no such simple answers. There are issues (both concerns and advantages) that participants clearly attributed to privatization. Other issues, some participants acknowledged, existed before privatization and continue to exist.

\section{Conclusions}

This research provides stakeholder views of privatized fostercare services in Kansas. Participants noted both positive and negative aspects of privatization and its impact on access to services. Concerning service access, participants in this research revealed the following needs: (a) Mental-health services and other preventive services should be available and accessible to youth and their families before crises occur; (b) youths should be in placements that are appropriate to their needs; (c) families should receive appropriate services while their children are in out-of-home placement and youths and their families 
should receive aftercare services when youths return home. In addition, study results revealed the need for (a) better communication and collaboration among service providers from the state agency and the private agencies, (b) attention to caseload levels in the child-welfare agencies, and (c) continued assessment and evaluation of the privatized system and its impact on outcomes for children and families.

\section{ABOUT THE AUTHORS}

KRISTEN R. HUMPHREY, LMSW, PhD, is a consultant and writer with an interest in family support, foster care, and social work education. ANN P. TURNBULL, EdD, and H. RUTHERFORD TURNBULL III, LLM, are co-directors of the Beach Center on Disability and professors in the Department of Special Education at the University of Kansas. Address: Kristen R. Humphrey, Beach Center on Disability, University of Kansas, 1200 Sunnyside Ave., Lawrence, KS 66045.

\section{NOTE}

The National Institute on Disability and Rehabilitation Research funded this research (H133B980050).

\section{REFERENCES}

Abma, T. A. (1998). Storytelling as inquiry in a mental hospital. Qualitative Health Research, 8, 821-838.

Ball, A. F. (1998). The value of recounting narratives: Memorable learning experiences in the lives of inner-city students and teachers. Narrative Inquiry, 8(1), 151-180.

Banyard, V., \& Miller, K. E. (1998). The powerful potential of qualitative research for community psychology. American Journal of Community $P_{s y-}$ chology; 26, 485-504.

Barbell, K. (1995). Foster care today: A briefing paper. Washington, DC: Child Welfare League of America.

Berg, B. L. (1998). Qualitative research methods for the social sciences (3rd ed.), Boston: Allyn \& Bacon.

Blackstone, E. A., Buck, A. J., \& Hakim, S. (2004). Privatizing adoption and foster care: Applying auction and market solutions. Retrieved April 25, 2004, from hitp://oll.temple.edu/economics/wkpapers.htm

Blumberg, E., Landsverk, J., Ellis-MacLeod, E., Ganger, W., \& Culver, S. (1996). Use of the public mental health system by children in foster care: Client characteristics and service use patterns. Public Interest Law Reporter, 23, 389-405.

Brand, A. E., \& Brinich, P. M. (1999). Behavior problems and mental health contacts in adopted, foster, and nonadopted children. Journal of Child Psychology and Psychiatry; and Allied Disciplines, 40, 1221-1229.

Breda, K. L., Anderson, M. A., Hansen, L., Hayes, D., Pillion, C., \& Lyon, P. (1997). Enhanced nursing autonomy through participatory action research. Nursing Outlook, 45, 76-81.

Clausen, J. M., Landsverk, J., Ganger, W., Chadwick, D., \& Litrownik, A. (1998). Mental health problems of children in foster care. Journal of Child and Family Studies, 7, 283-296.

Courtney, M. E. (2000). Managed care and child welfare services: What are the issues? Children and Youth Services Review, 22(2), 87-91.

Denzin, N. K. (1994). The art and politics of interpretation. In N. K. Denzin \& Y. S. Lincoln (Eds.), Handbook of qualitative research (pp. 500-515). Thousand Oaks, CA: SAGE.

Docherty, S., \& Sandelowski, M. (1999). Focus on qualitative methods: Interviewing children. Research in Nursing \& Health, 22(2), 177-185.

Dore, M. M. (1999). Emotionally and behaviorally disturbed children in the child welfare system: Points of preventive intervention. Children and Youth Services Review, 21(1), 7-29.
Drissel, A. B. (1997). Managed care and children and family services: A guide for state and local officials. Baltimore: The Annie E. Casey Foundation.

Embry, R. A., Buddenhagen, P., \& Bolles, S. (2000). Managed care and child welfare: Challenges to implementation. Children and Youth Services Review, 22(2), 93-116.

Erlandson, D. A., Harris, E. L., Skipper, B. L., \& Allen, S. D. (1993). Doing naturalistic inquiry: A guide to methods. Newbury Park, CA: SAGE.

The Ethnograph. (Version 5.0)(1998). [Computer software]. Amherst, MA: Qualis Research Associates.

Gatenby, B., \& Humphries, M. (1996). Feminist commitments in organisational communication: Participatory action research as feminist praxis. Australian Journal of Communication, 23(2), 73-87.

Goldhaber, M. D. (2000). Giving up their kids: Mentally ill children, and the custody crisis you never heard of. The National Law Journal. Retrieved May 1, 2004, from www.law.com

Hartnett, M. A., Falconnier, L., Leathers, S., \& Testa, M. (1999). Placement stability study. Urbana, IL: University of Illinois at Urbana-Champaign.

Hones, D. F. (1998). Known in part: The transformational power of narrative inquiry. Qualitative Inquiry, 4(2), 225-248.

Honey, M. A. (1987). The interview as text: Hermeneutics considered as a model for analysing the clinically informed research interview. Human Development, 30, 69-82.

Huberman, A. M., \& Miles, M. B. (1994). Data management and analysis methods. In N. K. Denzin \& Y. S. Lincoln (Eds.), Handbook of qualitative research (pp. 428-444). Thousand Oaks, CA: SAGE.

Humphrey, K. R. (2002). The impact of service access on out-of-home placement for youth with emotional disabilities and their families (Doctoral dissertation, University of Kansas, 2002). Dissertation Abstracts International, 63(10A), 3728.

James Bell Associates. (1999). External evaluation of the Kansas child welfare system: 1st quarter report (January-March 1999). Arlington, VA: Author.

James Bell Associates. (2001a). External evaluation of the Kansas child welfare system: July 2000-June 2001, FY 2001 Final report. Arlington, VA: Author.

James Bell Associates. (2001b). External evaluation of the Kansas child welfare system: July-December 2000, FY 2001 Second quarterly report. Arlington, VA: Author.

Jones, L. (1998). The social and family correlates of successful reunification of children in foster care. Children and Youth Services Review, 20, 305-323.

Julian, D. A., Julian, T. W., Mastrine, B. J., Wessa, P., \& Atkinson, E. (1992). Residential and community treatment services utilized by a sample of youth with severe emotional disturbances. American Journal of Community Psychology, 20, 799-809.

Kadushin, A. (1990). The social work interview. New York, NY: Columbia University Press.

Kansas Action for Children. (1998). Privatization of child welfare services in Kansas: A child advocacy perspective. Topeka, KS: Author

Kansas Chapter, National Association of Social Workers. (1997). Kansans talk back: Early responses to the move to privatization of child welfare services [Report]. Topeka, KS: Author.

Knitzer, J. (2001). Building services and systems to support the healthy emotional development of young children-An action guide for policymakers. New York, NY: National Center for Children in Poverty.

Legislative Division of Post Audit. (1998a). Performance audit report: Assessing how well the foster care program in Kansas is working, part I: Services and placements (No. 99-03). Topeka, KS: Author.

Legislative Division of Post Audit. (1998b). Performance audit report: Assessing how well the foster care program in Kansas is working, Part II (No. 99-03.2). Topeka, KS: Author.

Legislative Division of Post Audit. (1998c). Performance audit report: Verifying information provided by the Department of Social and Rehabilitation Services on its compliance with the terms of the foster care lawsuit settlement agreement: Monitoring Report $\# 8$ (No. 98-34.2). Topeka, KS: Author.

Legislative Division of Post Audit. (2001). Performance audit report: The State's adoption and foster care contracts: Reviewing selected financial and service isstes (No. 01-08). Topeka, KS: Author. 
Lincoln, Y. S., \& Guba, E. G. (1985). Naturalistic inquiry. Newbury Park, CA: SAGE.

Marshall, C., \& Rossman, G. B. (1995). Designing qualitative research (2nd ed.). Newbury Park, CA: SAGE.

McCullough, C., \& Schmitt, B. (1999). Managed care and privatization child welfare tracking project: 1998 state and county survey results. Washington, DC: Child Welfare League of America.

McCullough, C., \& Schmitt, B. (2000). Managed care and privatization: Results of a national survey. Children and Youth Services Review, 22(2), 117-130.

McKelvey, R. S. (1988). A continuum of mental health care for children and adolescents. Hospital o Community Psychiatry, 39, 870-873.

McMurtry, S. L., \& Gwat-Yong, L. (1992). Differential exit rates of minority children in foster care. Social Work Research \& Abstracts, 28(1), 42-48.

Miles, M. B., \& Huberman, A. M. (1994). Qualitative data analysis: An expanded sourcebook (2nd ed.). Thousand Oaks, CA: SAGE.

Morse, J. M. (1994). Designing funded qualitative research. In N. K. Denzin \& Y. S. Lincoln (Eds.), Handbook of qualitative research (pp. 220-235). Thousand Oaks, CA: SAGE.

NASW Task Force on Social Work Practice in Child Protection. (1997). NASW Standards for Social Work Practice in Child Protection. Washington, DC: NASW.

National Education Association. (2004a). 'No Child Left Behind'Act/ESEA. Retrieved April 6, 2004, from http://www.nea.org/esea/

National Education Association. (2004b). Privatization. Retrieved April 6, 2004, from http://www.nea.org/privatization/

Nightingale, D. S., \& Pindus, N. (1998). Privatization of public social services: $A$ background paper. Washington, DC: The Urban Institute

Oliver, M. N. I. (2002). Privatizing Medicaid-funded mental health services: Trading old political challenges for new ones. The American Journal of Orthopsychiatry, 72, 324-330

Olsen, L. J. (1982). Predicting the permanency status of children in foster care. Social Work Research \& Abstracts, 18(1), 9-20

Patton, M. Q. (1990). Qualitative evaluation and research methods (2nd ed.). Newbury Park, CA: SAGE.

Penuel, W. R., \& Freeman, T. (1997). Participatory action research in youth programming: A theory in use. Child and Youth Care Forum, 26, 175-185.

Petr, C. G., \& Barney, D. D. (1993). Reasonable efforts for children with disabilities: The parents' perspective. Social Work, 38, 247-254.

Pheatt, M., Douglas, B., Wilson, L., Brook, J., \& Berry, M. (2000). Family preservation services under managed care: Current practices and future directions. Family Preservation Journal, 5(1), 21-39.

Public Employees Federation. (2004). Privatization:A fight back handbook. Retrieved April 13, 2004, from http://www.pef.org/privabackground.htm

Reason, P. (1998). Three approaches to participative inquiry. In N. K. Denzin \& Y. S. Lincoln (Eds.), Strategies of qualitative inquiry (pp. 261-291). Thousand Oaks, CA: SAGE.

Roberts-DeGennaro, M. (1996). An interdisciplinary training model in the field of early intervention. Social Work Education, 18(1), 20-29.

Rosenfeld, A. A., Pilowsky, D. J., Fine, P., Thorpe, M., Fein, E., Simms, M. D., et al. (1997). Foster care: An update. Journal of the American Academy of Child and Adolescent Psychiatry, 36, 448-457.

Rothschild, S. (2001, October 4, 2001). SRS facing slashed budget. Lawrence Journal World, p. al.

Saxe, L., Cross, T., \& Silverman, N. (1988). Children's mental health: The gap between what we know and what we do. The American Psychologist, 43, 800-807.

Scallet, L., Brach, C., \& Steel, E. (Eds.). (1997). Managed care: Challenges for children and family services. Baltimore: The Annie E. Casey Foundation.
Schmidt-Tieszen, A., \& McDonald, T. (1998). Children who wait: Long term foster care or adoption? Children and Youth Services Review, 20(1/2), 13-28.

Schor, E. L. (1988). Foster care. The Pediatrics Clinics of North America, 35, $1241-1252$.

Seaberg, J. R., \& Tolley, E. S. (1986). Predictors of the length of stay in foster care. Social Work Research o Abstracts, 22(3), 11-17.

Sheila A. v. Finney. (1987). docket 89-CV-33, District Court, Shawnee County, KS.

Shepherd, J. F. (1997). Testimony as to impact of privatization on children in need of care and their families. In Kansas Chapter National Association of Social Workers (Ed.), Kansans talk back: Early responses to the move to privatization of child welfare services [Report]. Topeka: Kansas Chapter National Association of Social Workers.

Snell, L. (2000). Child-ivelfare reform and the role of privatization (No. 271). Los Angeles, CA: Reason Public Policy Institute.

Social and Rehabilitation Services of Kansas. (1996). Commutrity forum: Privatizing child welfare. Topeka, KS: SRS Office of Design.

Stake, R. E. (1998). Case studies. In N. K.Denzin. \&Y. S. Lincoln (Eds.), Strategies of qualitative inquiry (pp. 86-109). Thousand Oaks, CA: SAGE.

Taylor, S. J., \& Bogdan, R. (1998). Introduction to qualitative research methods: A guidebook and resource. New York: Wiley.

Tucci, A. (2001). Public child welfare agencies face staffing problems. Washington DC: American Public Human Services Association.

Turnbull, A. P., Friesen, B. J., \& Ramirez, C. (1998). Participatory action research as a model for conducting family research. JASH, 23(3), 178-188.

U.S. Department of Health and Human Services. (1997). National study of protective preventive and reunification services delivered to children and their families. Washington, DC: U.S. Government Printing Office.

U.S. Department of Health and Human Services. (1998). Child welfare outcomes 1998: Annual report. Washington, DC: Author.

U.S. General Accounting Office. (1997). Foster care: State efforts to improve the permanency planning process show some promise (No. GAO/HEHS-9773). Washington, DC: U.S. Government Printing Office.

U.S. General Accounting Office. (2003a). Child welfare and juvenile justice: Federal agencies could play a stronger role in helping states reduce the number of children placed solely to obtain mental health services (No. GAO-03397). Washington, DC: U.S. Government Printing Office.

U.S. General Accounting Office. (2003b). HHS could play a greater role in helping child welfare agencies recruit and retain staff (No. GAO-03-357). Washington, DC: U.S. Government Printing Office.

U.S. Public Health Service. (2000). Report of the Surgeon General's Conference on Children's Mental Health: A national action agenda. Washington, DC. U.S. Government Printing Office.

Waugaman, W.R. (1994). Professionalization and socialization in interprofessional collaboration. In R. M. Casto \& M. C. Julia (Eds.), Interprofessional care and collaborative practice (pp. 23-31). Pacific Grove, CA: Brooks/ Cole.

Ways and Means Committee. (1998). 1998 Green Book (No. WMCP:105-7). Washington, DC: Committee on Ways and Means, U.S. House of Representatives.

Woodhouse, L. D., \& Livingood, W.C. (1991). Exploring the versatility of qualitative design for evaluating community substance abuse prevention projects. Qualitative Health Research, 1(4), 434-445.

Wulczyn, F. W. (2000). Federal fiscal reform in child welfare services. Children and Youth Services Review, 22(2), 131-159.

Yin, R. K. (1994). Case study research: Design and methods (2nd ed., Vol. 5). Newbury Park, CA: SAGE. 


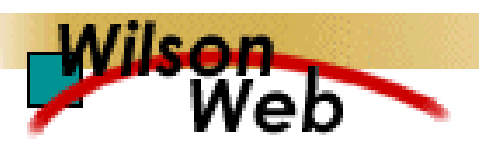

\section{COPYRIGHT INFORMATION}

TITLE: Perspectives of Foster-Care Providers, Service Providers, and Judges $\mathrm{Re}$

SOURCE: Journal of Disability Policy Studies 17 no1 Summ 2006

PAGE(S): 2-17

WN: 0619610141003

The magazine publisher is the copyright holder of this article and it is reproduced with permission. Further reproduction of this article in violation of the copyright is prohibited. To contact the publisher: http://www.proedinc.com/jdps.html

Copyright 1982-2006 The H.W. Wilson Company. All rights reserved. 